\title{
Cumulative experience of the anterior approach in robot-assisted thoracic surgery for lung cancer patients
}

\author{
Koji Yamazaki ${ }^{1}$, Gouji Toyokawa ${ }^{1}$, Yuka Kozuma ${ }^{1}$, Fumihiro Shoji ${ }^{1}$, Mototsugu Shimokawa ${ }^{2,3}$, \\ Sadanori Takeo ${ }^{1}$ \\ ${ }^{1}$ Department of Thoracic Surgery, Clinical Research Institute, National Hospital Organization, Kyushu Medical Center, Fukuoka, Japan; \\ ${ }^{2}$ Department of Biostatistics, Yamaguchi University Graduate School of Medicine, Yamaguchi, Japan; ${ }^{3}$ Clinical Research Institute, National Hospital \\ Organization, National Kyushu Cancer Center, Fukuoka, Japan \\ Contributions: (I) Conception and design: K Yamazaki, S Takeo; (II) Administrative support: None; (III) Provision of study materials or patients: K \\ Yamazaki, G Toyokawa, Y Kozuma, F Shoji; (IV) Collection and assembly of data: K Yamazaki, G Toyokawa, Y Kozuma, F Shoji; (V) Data analysis \\ and interpretation: K Yamazaki, G Toyokawa, M Shimokawa; (VI) Manuscript writing: All authors; (VII) Final approval of manuscript: All authors. \\ Correspondence to: Koji Yamazaki. Department of Thoracic Surgery, Clinical Research Institute, National Hospital Organization, Kyushu Medical \\ Center, 1-8-1 Jigyohama, Chuo-ku, Fukuoka 810-8563, Japan. Email: yamakan521@gmail.com.
}

Background: Robot-assisted thoracic surgery (RATS) lobectomy for lung cancer is now performed all around the world. The camera and robotic devices are generally inserted from a low position via the thorax. We previously reported our original anterior approach (AA) for performing RATS lobectomy with a camera and robotic devices inserted via the anterior chest wall. However, whether AA is comparable or superior to the conventional approach (CA) remains unclear.

Methods: A total of 108 patients who underwent RATS lobectomy were included in the current study. We compared the AA with the CA for performing RATS lobectomy in terms of the operative and postoperative features, such as total operation/console time, blood loss and postoperative complications.

Results: Eighty-seven and 21 patients underwent the AA and CA in RATS lobectomy, respectively. The console and total operation time were significantly shorter in the AA group than in the CA group for RATS lobectomy (median console time: AA vs. CA, 112 vs. $148 \mathrm{~min}, \mathrm{P}=0.0001$; median total operation time: AA vs. CA, 193 vs. $243 \mathrm{~min}, \mathrm{P}=0.0002$ ), especially left upper lobectomy. Intraoperative blood loss and the frequency of postoperative complications were significantly reduced in the AA group compared with the CA group (median intraoperative blood loss: AA vs. CA, 20 vs. $105 \mathrm{~mL}, \mathrm{P}<0.0001$; postoperative complications: AA vs. CA, $8.0 \%$ vs. $28.6 \%, \mathrm{P}=0.0088$ ).

Conclusions: These results suggest that our AA of RATS lobectomy can be very easily and safely performed.

Keywords: Robotic-assisted thoracic surgery (RATS); lobectomy; anterior approach (AA); lung cancer

Submitted May 17, 2021. Accepted for publication Jul 29, 2021.

doi: $10.21037 /$ jtd-21-821

View this article at: https://dx.doi.org/10.21037/jtd-21-821

\section{Introduction}

Robot-assisted thoracic surgery (RATS) lobectomy using da Vinci Surgical System for lung cancer was first reported by Melfi et al. in the 2002 (1). With regards to the feasibility and oncological radicality, RATS lobectomy has been considered comparable with open lobectomy and video- assisted thoracic surgery (VATS) $(2,3)$. The number of patients undergoing RATS lobectomy has been increasing yearly.

Commonly, RATS lobectomy is performed by a conventional approach (CA) with the camera inserted from a low position via the thorax. However, some unique techniques are needed to perform RATS lobectomy. 
Therefore, if the camera could be inserted anteriorly or posteriorly, RATS lobectomy could be easily adapted for performance by many surgeons, especially those who are familiar with a standard open thoracotomy procedure.

Previously, we established our original anterior approach (AA) for performing RATS lobectomy with the insertion of the camera and robotic devices via the anterior chest wall using the da Vinci Si surgical system (Intuitive Surgical Inc., Sunnyvale, CA, USA) (4). We believe that this novel approach can make this operation very easy to perform and enable the operator to perform lobectomy like a standard open thoracotomy procedure. Furthermore, Funai et al. also reported the arrangement of ports inserted into the thoracic cavity to obtain a good intrathoracic visual field using a da Vinci Xi surgical system (Intuitive Surgical Inc.) (5). But their method seems different from our original AA in that their method is basically the normal port placement with the camera and posterior port slightly higher, suggesting that the $\mathrm{AA}$ is a completely novel port placement technique. Importantly, our original AA can offer good visualization of the head side of the superior pulmonary vein and first branches of the pulmonary artery (PA) on both the left and right sides, allowing not only surgeons but also assistants to handle such vessels safely. However, there are no reports comparing the AA with the CA.

We herein report data comparing the AA with the CA regarding operative and postoperative factors, with a focus safety.

We present the following article in accordance with the STROBE reporting checklist (available at https://dx.doi. org/10.21037/jtd-21-821).

\section{Methods}

\section{Study patients}

From April 2014 to July 2020, a total of 108 patients with primary lung cancer with clinical stage I non-small cell lung cancer or metastatic lung tumor underwent RATS lobectomy at the Department of Thoracic Surgery, National Hospital Organization, Kyushu Medical Center. From April 2014 to May 2018, 21 patients underwent the CA, whereas 87 patients underwent the AA between June 2018 and July 2020. Patients selected were scheduled for RATS lobectomy after an examination with total body contrast-enhanced computed tomography, positron emission tomography and endobronchial ultrasound-guided bronchoscopy and/ or mediastinoscopy, if needed. All patients were examined for operability with cardiopulmonary function tests. The study was conducted in accordance with the Declaration of Helsinki (as revised in 2013). This study was approved by our institutional review board (date: 2013/11/27; the Number of the Ethic Approval: 13-120). The requirement for written consent was waived because of the retrospective nature of the study.

\section{Surgical approaches}

In this study, only da Vinci Si surgical system (Intuitive Surgical Inc., Sunnyvale, CA, USA) was used. Two certified surgeons in Japan (K.Y. and F.S.) performed RATS lobectomy.

The AA was performed as described previously (4). Under general anesthesia and double-lumen intubation, the patients were placed in a lateral decubitus position. The shoulder and hip of the patients were covered with thick sponge to protect them from colliding with the robotic arms. We used a $30^{\circ}$ video-camera in a down-view manner. The camera port was placed at the 4th intercostal space on the anterior axillary line, the first arm-port at the 3rd intercostal space at the axilla, the second arm-port at the 6th intercostal space on the middle axillary line and the third arm-port at an inferior intercostal space, such as the 7 th, 8 th or 9 th-intercostal space, on the middle to posterior axillary line. Leaving a space of at least $6 \mathrm{~cm}$ between each port reduced the risk of arms colliding with each other. In addition, an access port was inserted at an inferior intercostal space, such as the 7 th, 8th or 9th-intercostal space, on the anterior axillary line (Figure 1).

An examination of the thoracic cavity, lavage cytology and tissue sampling as well as the confirmation of the position and depth of each port were performed with the usual VATS technique using a standard thoracoscope. The patient cart of the da Vinci Si system was rolled in from the dorsal side of the patient, and then each of the four arms was fixed to a port.

The instrument position remained the same, even during procedures for the hilar and interlobar space, and upper and lower mediastinum. An assistant surgeon used the access port to insert mechanical staplers and suction devices and to remove the dissected lymph nodes.

Carbon dioxide gas insufflation into thoracic cavity helped keep the lung down and the operative field wide. In all cases, systematic N2 lymph node dissection was performed after lobectomy according to the UICC classification (6). The resected pulmonary lobe was 
A

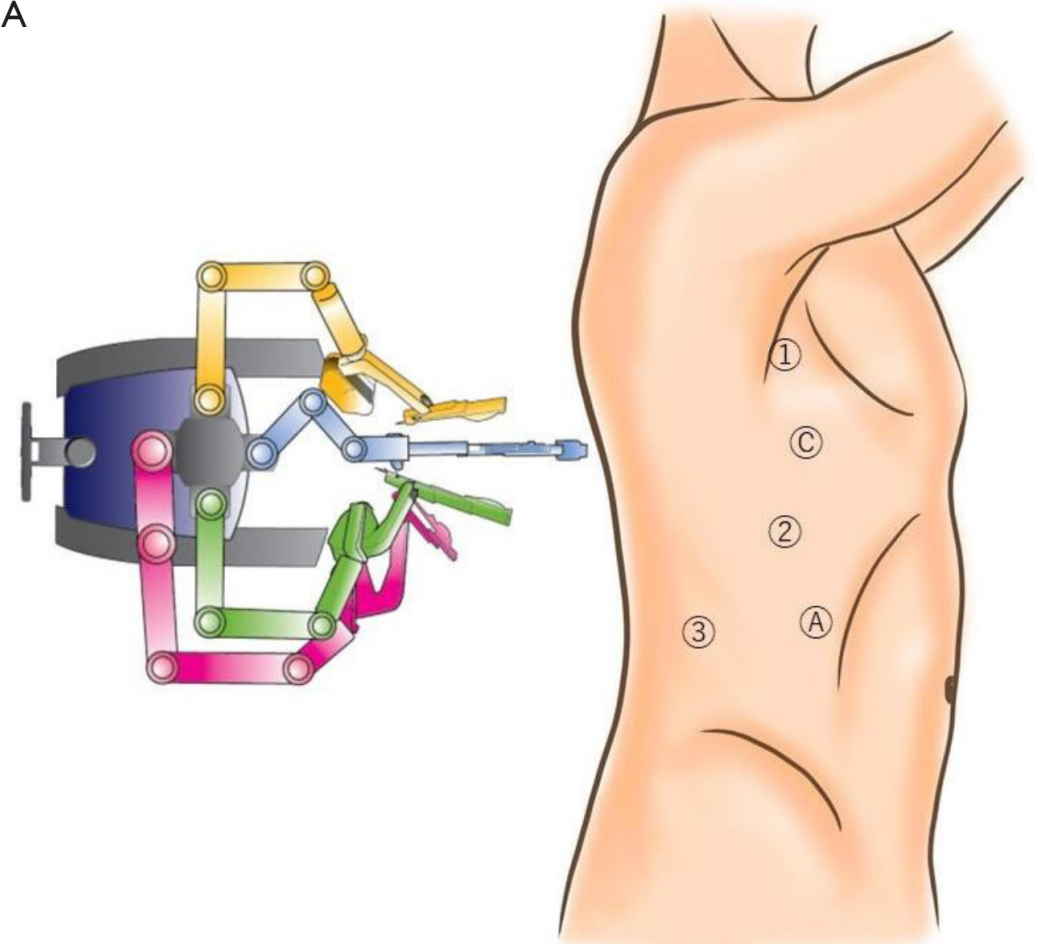

B

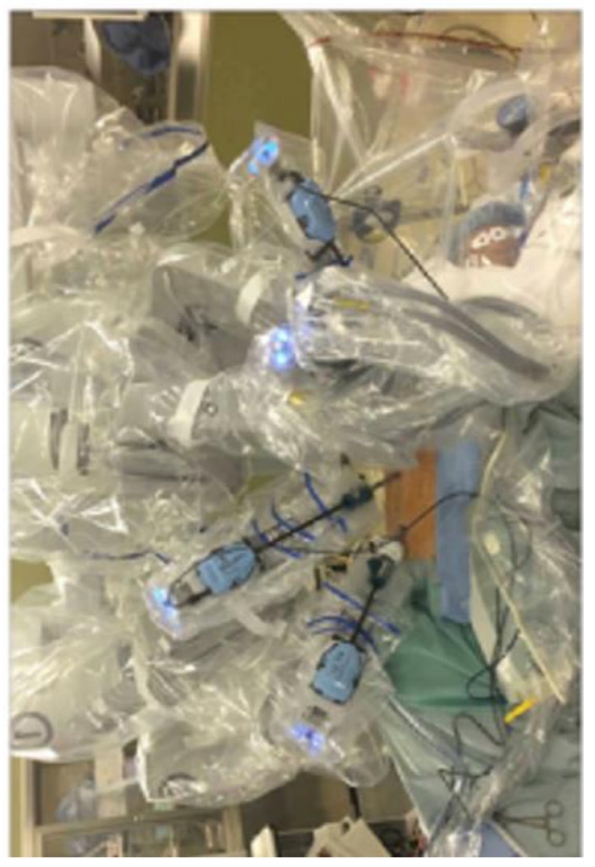

Figure 1 Anterior approach (AA) in robot-assisted thoracic surgery (RATS). (A) Schematic illustration and (B) actual images of RATS-AA. A, assist port; C, camera port; 1, first arm-port; 2, second arm-port; 3, third arm-port.

extracted using a specimen retrieval bag from one of the incisions that had been extended to approximately $3 \mathrm{~cm}$.

The CA was performed based on the widely adopted approach reported by Cerfolio et al. using the $0^{\circ}$ videocamera (Figure 2) (7).

Video 1 shows the differences in the visibility of the right superior trunk and the visibility of the left A3 between the $\mathrm{AA}$ and CA. Our institution adopted an anterior fissureless approach (AFT), which has been widely used to perform VATS and thoracotomy, when performing left upper lobectomy (LUL) and right upper lobectomy (RUL) (8).

\section{Factors analyzed}

The clinical features, including the age (years old) at surgery, sex, body height $(\mathrm{cm})$, body weight $(\mathrm{kg})$, preoperative diagnosis, clinical tumor-node-metastasis (TNM) stage (eighth edition of the lung cancer staging system) and surgical procedure, were retrospectively examined. Operative and postoperative features analyzed were as follows: surgical procedures, console time (min), total operation time (min), intraoperative blood loss ( $\mathrm{ml}$ ), total number of staples used, postoperative complications and timing of chest tube removal (days).

\section{Statistical analyses}

Student's $t$-test and the Mann-Whitney test (for data that were not normally distributed, such as console time and intraoperative blood loss) were used to analyze the associations between the surgical approach (AA or CA) and continuous data. The chi-squared test was used to analyze the associations between the surgical approach (AA or CA) and categorical variables. All of the statistical analyses were conducted using the JMP software program, version 12 (SAS Institute, Cary, NC, USA). P values of $<0.05$ were considered to indicate statistically significant differences.

\section{Results}

The clinical characteristics and operative/postoperative outcomes are shown in Table 1. The median age (range) was 69 (35-87) years. Among 108 patients, 55 (50.9\%) were female, and $53(49.1 \%)$ were male. The mean value 


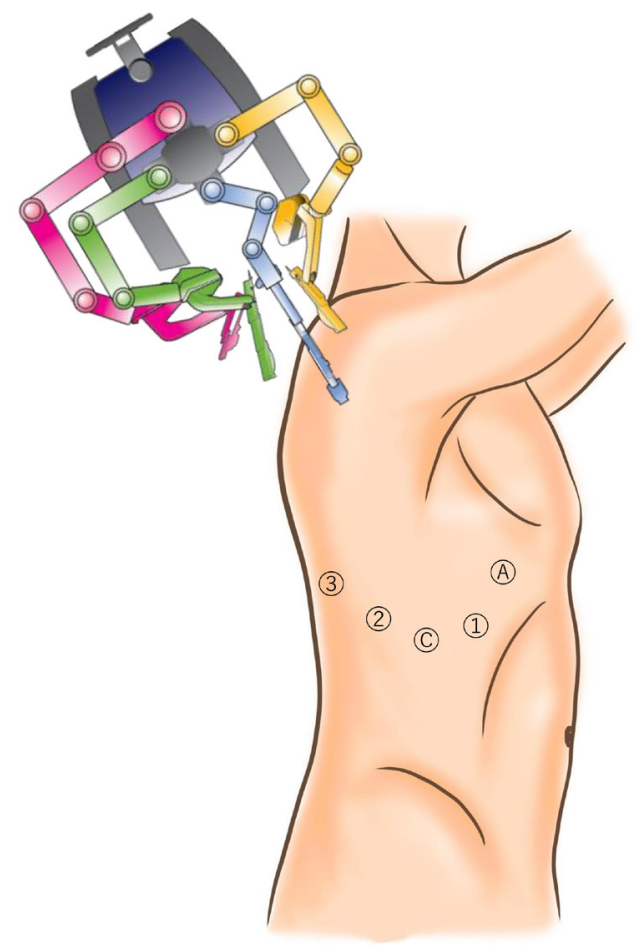

Figure 2 Schematic illustration of the conventional approach to perform robot-assisted thoracic surgery. A, assist port; C, camera port; 1, first arm-port; 2, second arm-port; 3, third arm-port.

of body height $(\mathrm{cm})$ was 159.5 , with a standard deviation of 9.7 , and the median body weight $(\mathrm{kg})$ was 57.2 (range, 40.3-96.9). A total of 105 (97.2\%) and 3 (2.8\%) patients were preoperatively diagnosed with primary lung cancer and metastatic lung tumor, respectively. The clinical stage of the primary lung cancer was as follows: T1aN0M0, 40 (37.0\%); T1bN0M0, 42 (38.8\%); T1cN0M0, 23 (24.2\%), respectively.

RUL, right middle lobectomy (RML), right lower lobectomy (RLL), LUL and left lower lobectomy (LLL) were performed in $34(31.5 \%), 8(7.4 \%), 23(21.3 \%)$, $27(25.0 \%)$ and $14(13.0 \%)$ patients, respectively. One $(0.9 \%)$ and one patient $(0.9 \%)$ underwent RML + S8 segmentectomy and RUL+S6 segmentectomy, respectively. The median console and total operation time $(\mathrm{min})$ were 121 (range, 61-292) and 209 (range, 99-419), respectively. The median intraoperative blood loss $(\mathrm{mL})$ was 24 (range, $0-2,988)$. Postoperative complications were identified in $13(12.0 \%)$, and the details were as follows: prolonged air leakage (PAL; $n=7)$, cerebral infarction $(n=2)$, chylothorax $(\mathrm{n}=1)$, pneumonia $(\mathrm{n}=1)$, anemia $(\mathrm{n}=1)$, surgical site
Table 1 Clinical characteristics and operative/postoperative outcomes

\begin{tabular}{|c|c|}
\hline Characteristics & $\mathrm{N}=108$ \\
\hline Age (years), median (range) & $69(35-87)$ \\
\hline \multicolumn{2}{|l|}{ Sex, n (\%) } \\
\hline Female & $55(50.9)$ \\
\hline Male & $53(49.1)$ \\
\hline Body height $(\mathrm{cm})$, mean \pm SD & $159.5 \pm 9.7$ \\
\hline Body weight $(\mathrm{kg})$, median (range) & $57.2(40.3-96.9)$ \\
\hline \multicolumn{2}{|l|}{ Preoperative diagnosis, n (\%) } \\
\hline Primary lung cancer & $105(97.2)$ \\
\hline Metastatic lung tumor & $3(2.8)$ \\
\hline \multicolumn{2}{|l|}{ Clinical stage of primary lung cancer, $\mathrm{n}(\%)$} \\
\hline T1aN0M0 & $40(38.1)$ \\
\hline T1bNOM0 & $42(40.0)$ \\
\hline T1cN0M0 & $23(21.9)$ \\
\hline \multicolumn{2}{|l|}{ Surgical procedures, n (\%) } \\
\hline RUL & $34(31.5)$ \\
\hline $\mathrm{RML}$ & $8(7.4)$ \\
\hline RLL & $23(21.3)$ \\
\hline LUL & $27(25.0)$ \\
\hline LLL & $14(13.0)$ \\
\hline Others* & $2(1.8)$ \\
\hline Console time (min), median (range) & $121(61-292)$ \\
\hline Total operation time (min), median (range) & $209(99-419)$ \\
\hline Intraoperative blood loss (mL), median (range) & $24(0-2988)$ \\
\hline Conversion into VATS or thoracotomy (n) & 0 \\
\hline Total number of stapler used, median (range) & $6(3-14)$ \\
\hline \multicolumn{2}{|l|}{ Postoperative complications, n (\%) } \\
\hline No & $95(88.0)$ \\
\hline Yes & $13(12.0)^{\star \star}$ \\
\hline $\begin{array}{l}\text { Duration of chest tube drainage (days), median } \\
\text { (range) }\end{array}$ & $1(1-17)$ \\
\hline $\begin{array}{l}\text { Postoperative hospital stay (days), median } \\
\text { (range) }\end{array}$ & $6(2-81)$ \\
\hline
\end{tabular}

*, others include RML + S8 segmentectomy and RUL + S6 segmentectomy; **, prolonged air leakage $(n=7)$, cerebral infarction $(n=2)$, chylothorax $(n=1)$, pneumonia $(n=1)$, anemia $(n=1)$, surgical site infection $(n=1)$ and syndrome of inappropriate secretion of $A D H(S I A D H ; n=1)$. One patient experienced both cerebral infarction and SIADH. SD, standard deviation; RUL, right upper lobectomy; RML, right middle lobectomy; RLL, right lower lobectomy; LUL, left upper lobectomy; LLL, left lower lobectomy; VATS, video-assisted thoracic surgery. 
infection $(\mathrm{n}=1)$ and syndrome of inappropriate secretion of $\mathrm{ADH}$ (SIADH; $\mathrm{n}=1$ ), one patient experienced both cerebral infarction and SIADH. The median total number of stapler used was 6 (range, 3-14). The chest tube was removed a median (range) of 1 (range, 1-17) days after the procedure. The median postoperative hospital stay (days) was 6 (range, 2-81).

The data comparing the clinical characteristics and operative/postoperative outcomes according to the surgical approach are shown in Table 2. With regard to the association between clinical characteristics and surgical procedures, no significant differences were observed between the CA and AA. Among 30 and 20 patients undergoing RATS RUL and LUL with the AA, AFT was performed in $30(100 \%)$ and $6(30.0 \%)$ patients, respectively, while no patients undergoing RATS RUL and LUL with the CA were resected with AFT, The console and total operation time were significantly shorter with the AA than with the CA for RATS lobectomy (median console time: $\mathrm{AA}$ vs. CA, 112 vs. $148 \mathrm{~min}, \mathrm{P}=0.0001$; median total operation time: AA vs. CA, 193 vs. $243 \mathrm{~min}$, $\mathrm{P}=0.0002)$. The median intraoperative blood loss and frequency of postoperative complications were significantly reduced with the AA compared with the CA (AA vs. CA, 20 vs. $105 \mathrm{~mL}, \mathrm{P}<0.0001$; and $8.0 \%$ vs. $28.6 \%, \mathrm{P}=0.0088$, respectively). No patients experienced conversion to VATS or thoracotomy. The median period for chest tube drainage was also significantly shorter with the AA than with the CA (AA vs. CA, 1 vs. 2 days, $\mathrm{P}<0.0001$ ). No significant differences were identified in the total number of staples used or the postoperative hospital stay between the two groups. Furthermore, excluding the data of RML $(\mathrm{n}=8), \mathrm{RML}+\mathrm{S} 8$ segmentectomy $(\mathrm{n}=1)$ and $\mathrm{RUL}+\mathrm{S} 6$ segmentectomy $(n=1)$, which were performed only in patients managed with the AA, did not affect these results (data not shown).

The console time and intraoperative blood loss according to the surgical procedures are shown in Table 3. Especially in patients undergoing LUL, both the console time and blood loss during operation were significantly reduced with the AA compared with the CA (median console time: AA vs. CA, 114 vs. 155 min, $\mathrm{P}=0.0128$; median intraoperative blood loss: AA vs. CA, 41 vs. $125 \mathrm{~mL}, \mathrm{P}=0.0108)$. Intraoperative blood loss was significantly less in RLL with the AA than with the CA (AA vs. CA, 8 vs. $101 \mathrm{~mL}, \mathrm{P}=0.0043$ ). In patients surgically treated with RUL and LLL, a nonsignificant but improving trend in the median console time was observed with the AA compared with the CA (RUL: AA vs. CA, 111 vs. 152 min, $\mathrm{P}=0.0542$; LLL: AA vs. CA, 91 vs. $169 \min , \mathrm{P}=0.0734)$.

\section{Discussion}

In the present study, we showed that the AA was significantly superior to the conventional CA with regard to the console and total operation time, intraoperative blood loss, postoperative complications and duration of chest tube drainage. In LUL in particular, which requires very careful division of the left $\mathrm{A} 3$, blood loss during the operation was significantly less with the AA than with the $\mathrm{CA}(\mathrm{P}=0.0108)$, which might be partly due to the nature of the AA, which offers a good view of the hilum for console surgeons. We feel that this good view of the hilum, especially pulmonary arteries and veins, offered by the AA enabled us to divide such vessels in a faster manner than the CA. It is also very important for assistants to be able to insert the stapler with the tip of the stapler easily visualized when using da Vinci Si. Furthermore, the AA may enable surgeons to easily and promptly secure proximity of the main trunk of both the right and left PA when experiencing critical hemorrhage from the PA. We believe that it is very important to dissect the proximal side of both the right and left PA prior to dividing the branches of the PA. Because of differences in the visibility of the hilum between the AA and CA, dissecting the proximal side of both the right and left PA appears to be less difficult with the AA than with the CA.

Typically, the operator works from the back or front of the patient during pulmonary surgery through thoracotomy, but variations in camera and instrument positions with unique techniques have been reported in VATS (9). The advent of the inferior approach of VATS was followed by the development of RATS lobectomy. In our department, we have adopted the VATS using the AA with the intention to perform operations in a manner similar to thoracotomy. We therefore attempted to perform this AA with RATS and succeeded in establishing the AA (4). As mentioned above, this approach can secure an optimal surgical view of the hilum and mediastinum, suggesting that we would be able to perform lobectomy nearly as safely and effectively with our procedures for VATS and thoracotomy. This may partly explain why the console and total operation time were significantly shorter with the AA than with the CA. In RUL and LUL, in particular, we adopted AFT and succeeded in standardizing this approach. For instance, when performing RUL, the fissures between the right upper and middle/ lower lobes are finally divided by stapling the parenchyma 
Table 2 A comparison of the clinical characteristics and operative/postoperative outcomes according to the surgical approach

\begin{tabular}{|c|c|c|c|}
\hline & \multicolumn{2}{|c|}{ Surgical approach } & $P$ value \\
\hline Age (years), median (range) & $68(41-79)$ & $70(35-87)$ & 0.1401 \\
\hline Female & $12(57.1)$ & $43(49.4)$ & \\
\hline Male & $9(42.9)$ & $44(50.6)$ & \\
\hline Body weight (kg), median (range) & $56.1(45.0-75.8)$ & $58.5(40.3-96.9)$ & 0.5143 \\
\hline Preoperative diagnosis, $\mathrm{n}(\%)$ & & & 0.3909 \\
\hline Primary lung cancer & $21(100.0)$ & $84(96.5)$ & \\
\hline Metastatic lung tumor & $0(0.0)$ & $3(3.5)$ & \\
\hline T1cN0M0 & $4(19.0)$ & $19(22.6)$ & \\
\hline Surgical procedures, n (\%) & & & 0.3413 \\
\hline RUL & $4(19.0)$ & $30(34.5)$ & \\
\hline RML & $0(0.0)$ & $8(9.2)$ & \\
\hline RLL & 7 (33.3) & $16(18.4)$ & \\
\hline LUL & 7 (33.3) & $20(23.0)$ & \\
\hline LLL & $3(14.3)$ & $11(12.6)$ & \\
\hline Others $^{*}$ & $0(0.0)$ & $2(2.3)$ & \\
\hline Intraoperative blood loss (mL), median (range) & $105(4-2,988)$ & $20(0-509)$ & $<0.0001$ \\
\hline Conversion into VATS or thoracotomy, n (\%) & & & - \\
\hline No & $21(100.0)$ & $87(100.0)$ & \\
\hline Yes & $0(0.0)$ & $0(0.0)$ & \\
\hline Total number of stapler used, median (range) & $6(4-12)$ & $6(3-14)$ & 0.9465 \\
\hline Postoperative complications, n (\%) & & & 0.0088 \\
\hline No & $15(71.4)$ & $80(92.0)$ & \\
\hline Yes & $6(28.6)^{\star \star}$ & $7(8.0)^{\star \star \star}$ & \\
\hline $\begin{array}{l}\text { Duration of chest tube drainage (days), median } \\
\text { (range) }\end{array}$ & $2(1-17)$ & $1(1-10)$ & $<0.0001$ \\
\hline Postoperative hospital stay (days), median (range) & $6(3-81)$ & $6(2-16)$ & 0.8560 \\
\hline
\end{tabular}

*, others include RML + S8 segmentectomy and RUL + S6 segmentectomy; **, prolonged air leakage $(n=4)$, chylothorax $(n=1)$ and cerebral infarction $(n=1)$; ${ }^{\star \star \star}$, prolonged air leakage $(n=3)$, syndrome of inappropriate secretion of ADH (SIADH; $\left.n=1\right)$, cerebral infarction $(n=1)$, pneumonia $(n=1)$, anemia $(n=1)$ and surgical site infection $(n=1)$. One patient experienced both cerebral infarction and SIADH. SD, standard deviation; RUL, right upper lobectomy; RML, right middle lobectomy; RLL, right lower lobectomy; LUL, left upper lobectomy; LLL, left lower lobectomy; VATS, video-assisted thoracic surgery. 
Table 3 Console time and intraoperative blood loss according to the surgical procedures

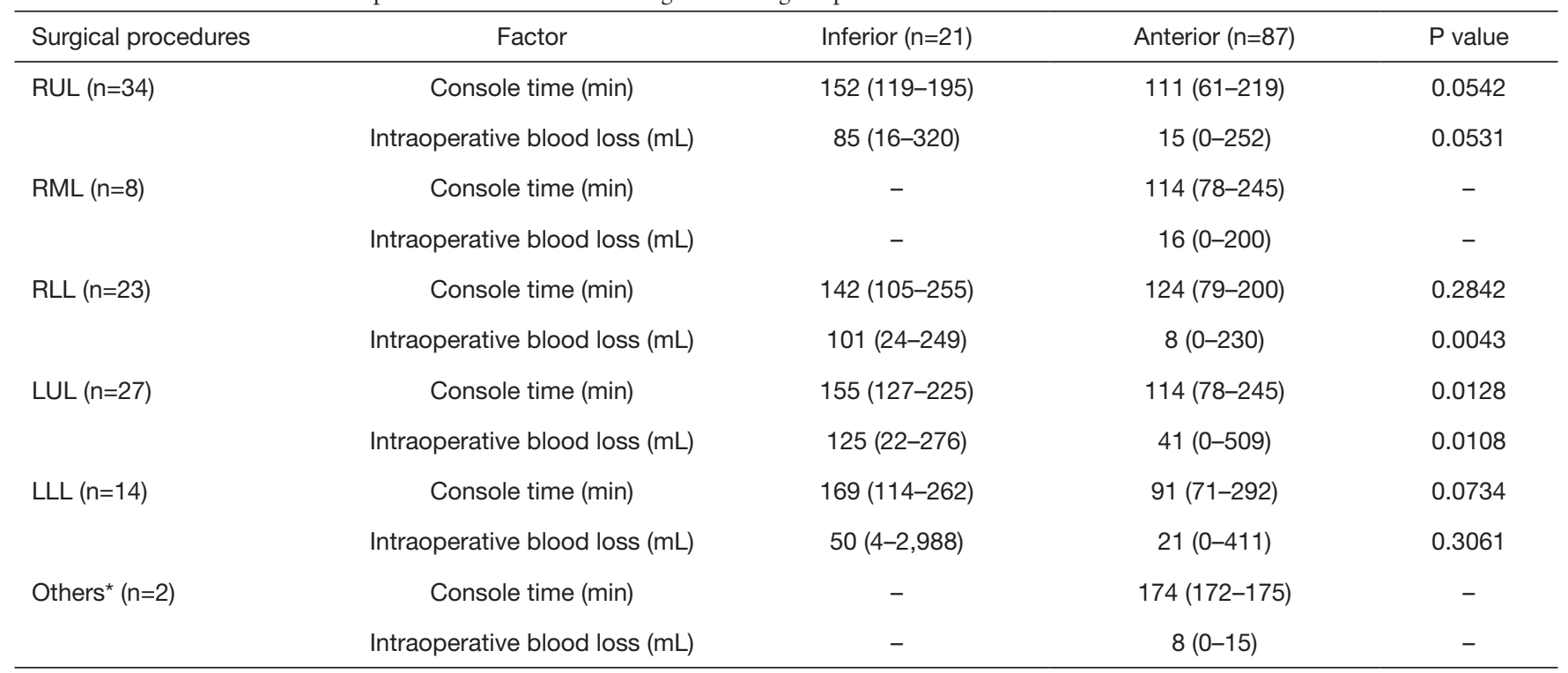

*, others include RML + S8 segmentectomy and RUL + S6 segmentectomy. RUL, right upper lobectomy; RML, right middle lobectomy; RLL, right lower lobectomy; LUL, left upper lobectomy; LLL, left lower lobectomy.

after the division of the upper branch of the superior pulmonary vein, superior trunk, ascending A2 and bronchus to the upper lobe. However, this manner of approach is considered difficult to perform by the CA because of the poor visibility of the hilum. This standardized AFT might lead to a significant reduction in the console and total operation time compared to the CA.

Furthermore, RUL by AFT does not require the division of the lung parenchyma to divide the ascending A2 and the bronchus to the upper lobe, and some reports have described RUL by thoracotomy using AFT as being significantly associated with a reduction in the incidence of PAL (10). In addition, regarding RUL by VATS, AFT was reported to result in a reduced incidence of PAL (11). In the present study, the analysis focusing on RUL by RATS revealed that the incidence of PAL was lower with the AA than with the CA (3.3\% vs. $25.0 \%)$, suggesting that AFT may be a useful technique when performing RATS RUL using the AA.

Despite the above mentioned merits, one of the limitations of the AA appears that the camera and instruments are close to the hilum and the lungs with this approach. Therefore, it is necessary for operators to perform examinations and handling carefully during procedures. Carbon dioxide gas insufflation into the thoracic cavity can resolve this concern by pushing down the lungs and keeping the operative field wide (7).
We experienced no cases of complications related to the wound with this approach, except for one case with surgical site infection. The AA requires the use of multiple intercostal spaces for thoracic ports. In contrast, the CA uses few intercostal spaces, as some ports are arranged in the same intercostal spaces. We have not investigated the postoperative pain, as both approaches are minimally invasive. However, we feel that the AA is less injurious for ribs than the CA because the intercostal spaces of the anterior chest wall are wide enough for the insertion of thoracic ports; the angle of the camera and the robotic arms are kept relatively obtuse with the AA, in contrast to the CA.

Using the da Vinci Xi system seems to make it more comfortable to perform RATS lobectomy with the AA thanks to technological improvements in the robotic arms and instruments $(2,12)$. When using the da Vinci Xi system, it should be clarified whether the robotic stapler can be used because there may not be enough distance between the chest wall and the articulation of the robotic stapler to allow it to be used. In some cases, an arrangement of port sites may be required. In the future, the acquisition of expertise with this approach will enable us to manage more advanced procedures, such as anastomosis of the bronchus and vessels.

The present study is associated with several limitations. First, this was a single-institutional retrospective study, and the number of patients in each approach was imbalanced. However, the patient characteristics in each group, 
such as the age, sex, body height and body weight, did not differ significantly. Although RML ( $\mathrm{n}=8), \mathrm{RML}+\mathrm{S} 8$ segmentectomy $(\mathrm{n}=1)$ and RUL+S6 segmentectomy $(\mathrm{n}=1)$ were performed only by the AA, excluding the data of these procedures did not affect the results. Second, due to the retrospective nature of our study, we were unable to eliminate all possible confounding factors that might impact the results. Third, the long-term outcomes, such as the recurrence-free and overall survivals, have yet to be clarified in this study. However, this study focused on the safety of the AA compared with the CA. Fourth, the period in which the AA and CA were performed was different: the AA and CA were performed between April 2014 and May 2018 and between June 2018 and July 2020, respectively. This suggests that the results obtained in this study were affected by improvements in the skills of surgeons over the course of time. These concerns may be addressed by a future prospective study comparing the AA with the CA.

In conclusion, we believe that our new AA is an effective technical method of performing RATS lobectomy. Further investigations will be needed to demonstrate the safety and usefulness of the AA, and we are planning to prospectively compare our AA with the CA.

\section{Acknowledgments}

We thank Mr. Brian Quinn for his critical comments on the manuscript.

Funding: None.

\section{Footnote}

Reporting Checklist: The authors have completed the STROBE reporting checklist. Available at https://dx.doi. org/10.21037/jtd-21-821

Data Sharing Statement: Available at https://dx.doi. org/10.21037/jtd-21-821

Peer Review File: Available at https://dx.doi.org/10.21037/ jtd-21-821

Conflicts of Interest: All authors have completed the ICMJE uniform disclosure form (available at https://dx.doi. org/10.21037/jtd-21-821). The authors have no conflicts of interest to declare.

Ethical Statement: The authors are accountable for all aspects of the work in ensuring that questions related to the accuracy or integrity of any part of the work are appropriately investigated and resolved. The study was conducted in accordance with the Declaration of Helsinki (as revised in 2013). This study was approved by our institutional review board (date: 2013/11/27; the Number of the Ethic Approval: 13-120). The requirement for written consent was waived because of the retrospective nature of the study.

Open Access Statement: This is an Open Access article distributed in accordance with the Creative Commons Attribution-NonCommercial-NoDerivs 4.0 International License (CC BY-NC-ND 4.0), which permits the noncommercial replication and distribution of the article with the strict proviso that no changes or edits are made and the original work is properly cited (including links to both the formal publication through the relevant DOI and the license). See: https://creativecommons.org/licenses/by-nc-nd/4.0/.

\section{References}

1. Melfi FM, Menconi GF, Mariani AM, et al.Early experience with robotic technology for thoracoscopic surgery. Eur J Cardiothorac Surg 2002;21:864-8.

2. Veronesi G, Novellis P, Voulaz E, et al.. Robot-assisted surgery for lung cancer: State of the art and perspectives. Lung Cancer 2016;101:28-34.

3. Kneuertz PJ, Cheufou DH, D'Souza DM, et al. Propensity-score adjusted comparison of pathologic nodal upstaging by robotic, video-assisted thoracoscopic, and open lobectomy for non-small cell lung cancer. J Thorac Cardiovasc Surg 2019;158:1457-66.e2.

4. Yamazaki K, Toyokawa G, Shoji F, et al. A novel technique for robotic-assisted lobectomy for lung cancer: The anterior approach. Interact Cardiovasc Thorac Surg 2020;30:328.

5. Funai K, Kawase A, Mizuno K, et al. Uniquely modified robotic-assisted thoracic surgery with good intrathoracic visual field. Ann Thorac Surg 2020;110:e435-6.

6. Rami-Porta R, Asamura H, Travis WD, et al. Lung cancer - major changes in the american joint committee on cancer eighth edition cancer staging manual. CA Cancer J Clin 2017;67:138-55.

7. Cerfolio RJ, Bryant AS, Minnich DJ. Starting a robotic program in general thoracic surgery: Why, how, and lessons learned. Ann Thorac Surg 2011;91:1729-36.

8. Temes RT, Willms CD, Endara SA, et al. Fissureless 
lobectomy. Ann Thorac Surg 1998;65:282-4.

9. Mun M, Nakao M, Matsuura Y, et al. Video-assisted thoracoscopic surgery lobectomy for non-small cell lung cancer. Gen Thorac Cardiovasc Surg 2018;66:626-31.

10. Ng T, Ryder BA, Machan JT, et al. Decreasing the incidence of prolonged air leak after right upper lobectomy with the anterior fissureless technique. J Thorac
Cardiovasc Surg 2010;139:1007-11.

11. Igai H, Kamiyoshihara M, Yoshikawa R, et al. The efficacy of thoracoscopic fissureless lobectomy in patients with dense fissures. J Thorac Dis 2016;8:3691-6.

12. Kim MP, Nguyen DT, Meisenbach LM, et al. Da vinci xi robot decreases the number of thoracotomy cases in pulmonary resection. J Thorac Dis 2019;11:145-53.

Cite this article as: Yamazaki K, Toyokawa G, Kozuma Y, Shoji F, Shimokawa M, Takeo S. Cumulative experience of the anterior approach in robot-assisted thoracic surgery for lung cancer patients. J Thorac Dis 2021;13(9):5487-5495. doi: $10.21037 /$ jtd-21-821 